\title{
Microbial Metabolism of Acetate, Propionate and Butyrate in Anoxic Sediment from the Colne Point Saltmarsh, Essex, U.K.
}

\author{
By M. TALAAT BALBA AND DAVID B. NEDWELL* \\ Department of Biology, University of Essex, Colchester CO4 3SQ, U.K.
}

(Received 2 October 1981; revised 6 January 1982)

\begin{abstract}
A gas chromatograph-gas proportional counting procedure has been developed to measure the in situ rates of metabolism of short-chain fatty acids in anaerobic saltmarsh sediment. The technique was used to determine the turnover rates of acetate, propionate and butyrate in sediment cores injected with ${ }^{14} \mathrm{C}$-labelled tracers and incubated at field temperature. Experiments showed that all three fatty acids were metabolized by micro-organisms present in the sediment, although an initial fast rate of disappearance of ${ }^{14} \mathrm{C}$ from the injected $\left[{ }^{14} \mathrm{C}\right]$ propionate and $\left[{ }^{14} \mathrm{C}\right]$ butyrate was partly due to exchange of the tracer between an extractable pool of fatty acids and a tightly bound fatty acid pool which was not extracted. Measurement of the rates of metabolism of acetate, propionate and butyrate in intact cores of sediment from the surface layer $(0-4 \mathrm{~cm})$ of a saltmarsh pan showed that carbon flow through the acetate pool was far greater than that through either propionate or butyrate. Only about $14 \%$ of the acetate could have been derived from propionate and butyrate, $86 \%$ being from other precursors. The rate of acetate turnover decreased markedly with increased depth, and at $20 \mathrm{~cm}$ was negligible. The turnover of propionate and butyrate was totally inhibited by the presence of $20 \mathrm{~mm}$-sodium molybdate, and their metabolism was attributed to the activity of sulphate-reducing bacteria.
\end{abstract}

\section{INTRODUCTION}

Volatile fatty acids are major intermediates in the anaerobic microbial breakdown of organic material and are commonly detected in anaerobic ecosystems such as the rumen (Bryant, 1977), sewage digesters (e.g. Hobson et al., 1974) and aquatic sediments (Miller et al., 1979). These acids play a key role in methanogenesis and sulphate reduction, the terminal processes of organic carbon mineralization in such ecosystems. For example, acetate has been considered to be the predominant precursor of methane in sewage digesters and in freshwater sediments (Wolfe \& Higgins, 1979) while acetate is oxidized to $\mathrm{CO}_{2}$ in marine sediments rich in sulphate (Sørensen et al., 1981; Banat et al., 1981).

Acetate, propionate and butyrate tend to be the principal volatile fatty acids in most anaerobic ecosystems, and certainly predominate in marine and intertidal sediments (Miller $e t$ al., 1979) including the Colne Point saltmarsh (Banat et al., 1981). However, consideration of concentrations alone cannot indicate their importance to the flow of carbon in sediments. Measurements of turnover constants are also necessary so that the rates of turnover can be calculated. The purpose of the present work was to develop a method for measuring turnover of these short-chain fatty acids, and hence to determine their importance to carbon flow within the sediment.

\section{METHODS}

Site and sampling method. Samples of sediment were taken from a saltmarsh pan in the Colne Point saltmarsh, Essex, U.K. The site has been described elsewhere (Nedwell \& Abram, 1978). For preparation of slurries, sediment 
was removed from the top $0-5 \mathrm{~cm}$ layer. Screw-topped jars were completely filled with the sediment in order to prevent aeration of the reduced anaerobic sediment during transport to the laboratory $(30 \mathrm{~min})$. When sediment from different depths was required, large vertical cores were removed from the pan sediment using PVC tubes ( $7 \mathrm{~cm}$ diameter) which had been previously split longitudinally and then taped back together. After returning to the laboratory each sediment core was exposed along its length by opening the split tube and subsamples were taken from the required depths. Subsamples were taken with $2 \mathrm{ml}$ polypropylene hypodermic syringes from which the needle ends had been removed. Each hypodermic syringe was immediately capped with a small Subaseal (Astell Hearson, London, U.K.) to exclude $\mathrm{O}_{2}$. These subsamples were placed in an incubator adjusted to the temperature of the sediment, which was measured in the field when the samples were taken. The hypodermic cores were left in the incubator for $30 \mathrm{~min}$ to reequilibrate to field temperature. Following this period of temperature equilibration each hypodermic core was injected with $50 \mu \mathrm{l}$ of a solution of ${ }^{14} \mathrm{C}$-labelled fatty acid dissolved in distilled water. The tracer solutions used were $\left[\mathrm{U}^{-14} \mathrm{C}\right.$ lacetate $\left[50 \mu \mathrm{Ci} \mathrm{m}^{-1} ; 58 \mathrm{mCi} \mathrm{mmol}^{-1}\left(2 \cdot 15 \mathrm{GBq} \mathrm{mmol}^{-1}\right)\right],\left[2-{ }^{14} \mathrm{C}\right]$ propionate $\left[20 \mu \mathrm{Ci} \mathrm{mi}^{-1} ; 53 \mathrm{mCi} \mathrm{mmol}^{-1} \quad\left(1.96 \mathrm{GBq} \mathrm{mmol}^{-1}\right)\right]$ and $\left[1{ }^{14} \mathrm{C}_{\text {butyrate }}\left[20 \mu \mathrm{Ci} \mathrm{m}^{-1} ; \quad 58 \mathrm{mCi} \mathrm{mmol}^{-1}\right.\right.$ $\left.\left(2 \cdot 15 \mathrm{GBq} \mathrm{mmol}^{-1}\right)\right]$ obtained from Amersham. The radiotracer solution was injected into replicate $2 \mathrm{ml}$ cores with a microsyringe, whose needle was slowly withdrawn as the tracer was injected in order to distribute the labelled acid as evenly as possible. The injected cores were immediately returned to the incubator and individual cores were withdrawn at timed intervals for extraction of the residual radiotracer. One of the injected cores was always processed immediately to provide a zero-time sample.

Extraction of fatty acids. At the end of the period of incubation the sediment in the hypodermic syringe was extruded into a test-tube containing $1 \mathrm{ml} 7 \mathrm{M}-\mathrm{HCl}$ which had been flushed with $\mathrm{O}_{2}$-free $\mathrm{N}_{2}$ (British Oxygen Company, U.K.). The tube was immediately capped and flushed for $15 \mathrm{~min}$ with a stream of $\mathrm{O}_{2}$-free $\mathrm{N}_{2}$ to remove any ${ }^{14} \mathrm{CO}_{2}$ and sulphide. The tube was centrifuged at $10000 \mathrm{~g}$ for $20 \mathrm{~min}$ and $1 \mathrm{ml}$ of the supernatant was then removed into a $5 \mathrm{ml}$ glass vial containing $0.4 \mathrm{~g} \mathrm{NaCl}$. A $1 \mathrm{ml}$ portion of diethyl ether was added, and the vial was capped, shaken for $1 \mathrm{~min}$, and then left in a cold cabinet overnight to ensure complete partition of any fatty acids into the ether layer.

In the case of slurry experiments a $2 \mathrm{ml}$ sample of slurry was acidified, centrifuged, and the supernatant extracted as for whole sediment samples.

Determination of radioactivity in fatty acid extracts. A $10 \mu \mathrm{l}$ sample of the ether extract was injected into a Pye Unicam (model GCD) gas chromatograph fitted with a $2 \mathrm{~m} \times 4 \mathrm{~mm}$ o.d. glass column packed with $15 \%$ SP-1220/1\% $\mathrm{H}_{3} \mathrm{PO}_{4}$ on Chromosorb WAW (100-120 mesh) (Supelco, Belletone, U.S.A.) and operated at an oven temperature of $145^{\circ} \mathrm{C}$. The carrier gas was $\mathrm{Ar} / \mathrm{CO}_{2}(95: 5, \mathrm{v} / \mathrm{v})$ at a flow rate of $50 \mathrm{ml} \mathrm{min}^{-1}$. At the end of the column a $1: 1$ splitter directed half of the effluent gas stream to a flame ionization detector to detect any volatile fatty acid peaks. The other half of the gas stream passed to a gas proportional counter (model 504, ESI Nuclear, U.K.) where the fatty acids were first oxidized on passage through a $\mathrm{CuO}$-packed column at $700{ }^{\circ} \mathrm{C}$ in a tube furnace. The radioactivity in each fatty acid peak was then counted as ${ }^{14} \mathrm{CO}_{2}$ as it passed through the counting chamber. An anticoincidence circuit corrected for background irradiation. The total number of radioactive disintegrations in each eluted fatty acid peak was determined with a digital event counter. Radioactivity is, therefore, expressed as the total number of counts in each acid peak, rather than as c.p.m. Retention times for both mass and radioactivity peaks were initially determined by the use of ether extracts of standard solutions of the ${ }^{14} \mathrm{C}$-labelled volatile fatty acids.

Calculation of turnover constant $(k)$. The radioactivity in the fatty acid peaks from a number of sequentially sampled cores was plotted as $\log _{10}$ (radioactivity) versus time. From the slope of the graph the turnover constant ( $k$ ) was calculated using the relationship: $k=2.303 \times \log _{10}\left(C_{0} / C\right) / t$, where $C_{0}$ is the initial count and $C$ is the count after time $t(h)$. Values for $k$ are given with standard errors shown in parentheses.

We checked to ensure that the gas proportional method of counting was reliable by comparing the turnover constant estimated by this method with that obtained from liquid scintillation counting. During the period when a radioactive fatty acid peak was passing out of the counting chamber the effluent gas stream from the gas proportional counter was bubbled into $\mathrm{CO}_{2}$-absorbing scintillant fluid $\left({ }^{14} \mathrm{C}\right.$ Absorber $\mathrm{P}$, Fisons, U.K.) in a vial. The trapped radioactivity was measured in a liquid scintillation counter (Packard Tri-Carb $460 \mathrm{C}$ ) and $k$ was determined from the plot of $\log _{10}$ (radioactivity) versus time.

Concentrations of fatty acids. Although small fatty acid peaks could be detected in the ether extracts of sediment, they were often too small to be accurately quantified without further concentration. Therefore $5 \mathrm{ml}$ of supernatant was obtained, as described previously, from a centrifuged larger sample of sediment from the required depths. This was adjusted to $\mathrm{pH} 11.0$ with $1 \mathrm{M}-\mathrm{NaOH}$ and freeze-dried. The solid residue was redissolved in $0.4 \mathrm{ml}$ water plus $0.1 \mathrm{ml} 1 \mathrm{M}-\mathrm{HCl}$ and extracted with $0.5 \mathrm{ml}$ ether. This gave a 10 -fold concentration of extracted fatty acids. Samples $(10 \mu \mathrm{l})$ of the ether extract were injected into the gas chromatograph and the peak areas of fatty acids were quantified with an electronic integrator (Chromatopac C-E/B, Shimadzu, Japan). The fatty acid concentrations were determined by comparison with injected samples of ether extracts of standard solutions of the fatty acids, which had been freeze-dried and extracted by the same method. 
Experiments. The method of measuring fatty acid turnover was tested initially using slurries of $50 \%(\mathrm{v} / \mathrm{v})$ saltmarsh sediment in deoxygenated seawater. Added radiotracer solutions could be homogeneously distributed in such slurries. The slurries were prepared using the precautions described by Banat et al. (1981) to ensure anaerobiosis and were maintained under $\mathrm{N}_{2} / \mathrm{CO}_{2}(80: 20, \mathrm{v} / \mathrm{v})$ at $6 \cdot 5{ }^{\circ} \mathrm{C}$. Portions $(100 \mu \mathrm{l})$ of either ${ }^{14} \mathrm{C}$-labelled acetate, propionate or butyrate were each added to $50 \mathrm{ml}$ of slurry, and $2 \mathrm{ml}$ samples of slurry were periodically removed with a syringe via a Subaseal to measure residual radioactivity.

Following this initial experiment the turnover of fatty acids was measured in the $2 \mathrm{ml}$ cores of undisturbed sediment in hypodermic syringes. The turnover of each of the three acids was measured in duplicate sets of cores, one set being first sterilized by autoclaving at $115^{\circ} \mathrm{C}$ for $20 \mathrm{~min}$ before injection of radiotracer solutions.

Finally, acetate turnover was measured in sediment cores taken from three depths within the sediment profile $(0-4,5-9,18-22 \mathrm{~cm})$.

Effect of increasing amounts of radiotracer solution upon the measured turnover constant. Cores ( $2 \mathrm{ml})$ of sediment were taken vertically down through the surface of the saltmarsh sediment (i.e. the $0-4 \mathrm{~cm}$ layer) with hypodermic syringes. Replicate cores of sediment were injected with either 50,100 or $150 \mu 1$ of tracer solution, and the turnover constants were measured for acetate, propionate and butyrate with each of these three injected volumes of tracer.

Slurry experiments with molybdate. It has been demonstrated previously (Banat et al., 1981) that the oxidation of acetate in the Colne Point saltmarsh sediment is caused by sulphate-reducing bacteria. Laanbroek \& Pfennig (1981) and Widdel (1980) have recently reported the isolation from marine sediments of new genera of sulphate-reducing bacteria able to metabolize propionate and butyrate. In order to determine whether the turnover of propionate and butyrate was also due to the activity of these newly described bacteria, we carried out experiments with slurries of saltmarsh sediment, prepared as described above, in the presence or absence of 20 mM-molybdate, an inhibitor of sulphate-reducing bacteria (Peck, 1959; Oremland \& Taylor, 1978). Pairs of flasks containing $50 \mathrm{ml}$ of sediment slurry were injected with $100 \mu \mathrm{l}$ of solutions of either ${ }^{14} \mathrm{C}$-labelled propionate or butyrate. To one of each pair of flasks was added $1 \mathrm{ml}$ of sodium molybdate solution to give a final concentration of $20 \mathrm{~mm}$-molybdate. The flasks were incubated at $6.5^{\circ} \mathrm{C}$. Turnover of the propionate or butyrate was followed by periodic removal of subsamples of slurry which were extracted to measure residual radioactivity in propionate or butyrate.

\section{RESULTS}

The initial experiment with sediment slurry gave linear semilogarithmic plots of residual radioactivity against time for all three fatty acids (Fig. 1). With propionate and butyrate, biphasic plots were obtained with an initially rapid rate of decrease of activity followed by a slower rate of decrease. Acetate showed only a single decreasing slope, however.

The comparison of the gas proportional counting method with liquid scintillation counting showed that our method of measuring radioactivity was satisfactory, the calculated $k$ values being identical for both methods $(P<0.001)$.

When turnover of labelled fatty acids was measured in cores of intact sediment (Fig. 2) the linearity of the semilogarithmic plots was again good. In the unautoclaved cores biphasic plots were again seen for propionate and butyrate. In the autoclaved cores, however, an initial decrease of activity was seen for propionate and butyrate, but after this there was no further decrease of activity of the extracted fatty acids. Autoclaving virtually eliminated any removal of acetate, although in the unautoclaved sediment a single linear decrease was observed. A small apparent decrease of $\left[\mathrm{U}-{ }^{14} \mathrm{C}\right]$ acetate activity in the autoclaved cores $[k=0.069$ $\left.( \pm 0.046) \mathrm{h}^{-1}\right]$ was associated with a single low data point after $120 \mathrm{~min}$, and if this point was ignored $k$ was 0 . The turnover constants for each fatty acid, together with their concentrations and calculated rates of metabolism are shown in Table 1 . The $k$ values for propionate and butyrate are those for the second, slower, rate of decrease (see Discussion).

Figure 3 illustrates the values of $k$ obtained for turnover of acetate, propionate or butyrate in sediment cores injected with different amounts of radiotracer solution. The value of $k$ decreased with increasing amount of radiotracer, a result also reported by Ansbaek \& Blackburn (1980) for turnover of acetate in marine sediment. Ideally, it would have been better to have injected a constant volume of solution containing increasing concentrations of labelled fatty acids but this was prohibitively expensive with the amounts of radiotracers 


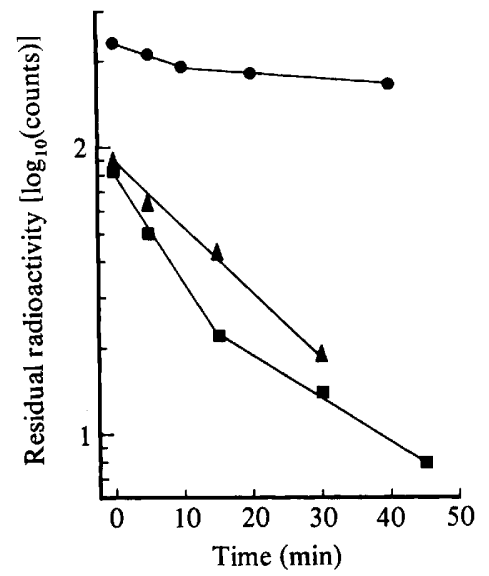

Fig. 1

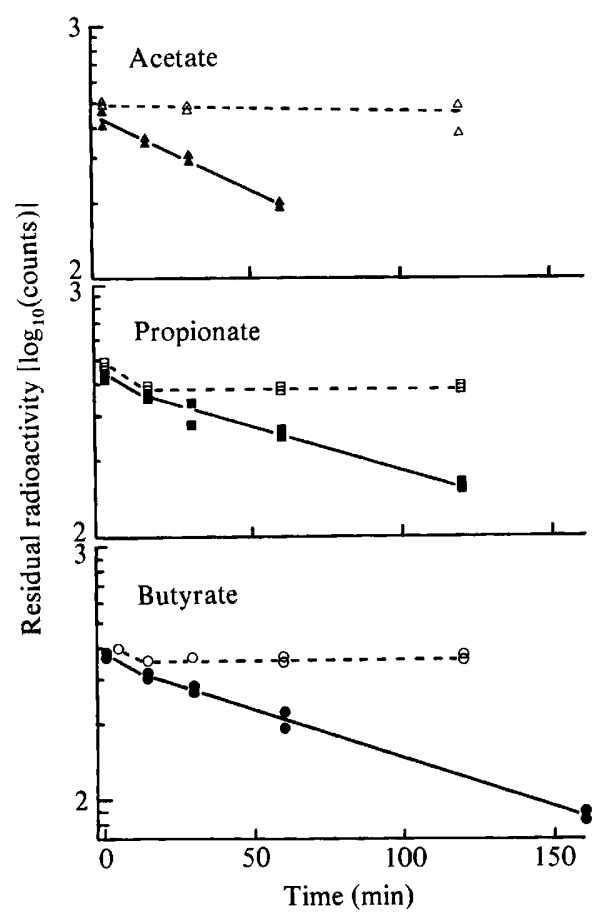

Fig. 2

Fig. 1. Turnover of $\left[\mathrm{U}-{ }^{14} \mathrm{C}\right]$ acetate $(\Delta),\left[2-{ }^{14} \mathrm{C}\right]$ propionate $(\square)$ and $\left[1-{ }^{14} \mathrm{C}\right]$ butyrate $(O)$ in slurry $(50 \%$, $\mathrm{v} / \mathrm{v})$ of saltmarsh sediment in deoxygenated seawater at $6.5^{\circ} \mathrm{C}$. Turnover constants $(k)$ for the microbiological turnover of injected radiotracers were: $\left[\mathrm{U}^{-14} \mathrm{C}\right]$ acetate, $2.98( \pm 0.13) \mathrm{h}^{-1}, r=0.99$; $\left[2-{ }^{14} \mathrm{C}\right]$ propionate, $2.0( \pm 0.06) \mathrm{h}^{-1}, r=1.0 ;\left[1-^{14} \mathrm{C}\right]$ butyrate, $0.28( \pm 0.01) \mathrm{h}^{-1}, r=1.0$. For propionate and butyrate the turnover data refer only to the second slope, which is the result of microbiological removal of radiotracer.

Fig. 2. Turnover of $\left[\mathrm{U}-{ }^{14} \mathrm{C}\right]$ acetate $(\Delta, \Delta),\left[2-{ }^{14} \mathrm{C}\right]$ propionate $(\square, \square)$ and $\left[1{ }^{14} \mathrm{C}\right]$ butyrate $(O, O)$ in cores of intact surface $(0-4 \mathrm{~cm})$ sediment at $6.5^{\circ} \mathrm{C}$. Open symbols indicate autoclaved sediment cores; closed symbols indicate unautoclaved cores. Turnover constants $(k)$ for the microbiological phase of fatty acid turnover in the unautoclaved cores were: [U- ${ }^{14} \mathrm{C}$ ]acetate, $0.78( \pm 0.05) \mathrm{h}^{-1}, r=0.98$; $\left[2 .{ }^{14} \mathrm{C}\right]$ propionate, $0.51( \pm 0.07) \mathrm{h}^{-1}, r=0.94 ;\left[1{ }^{14} \mathrm{C}\right]$ butyrate, $0.58( \pm 0.02) \mathrm{h}^{-1}, r=0.99$. For propionate and butyrate the turnover data refer only to the second slope, which is the result of microbiological removal of radiotracer.

Table 1. Rates of microbial metabolism of acetate, propionate and butyrate in intact sediment cores from the surface $0-4 \mathrm{~cm}$ of saltmarsh pan at $6.5^{\circ} \mathrm{C}$

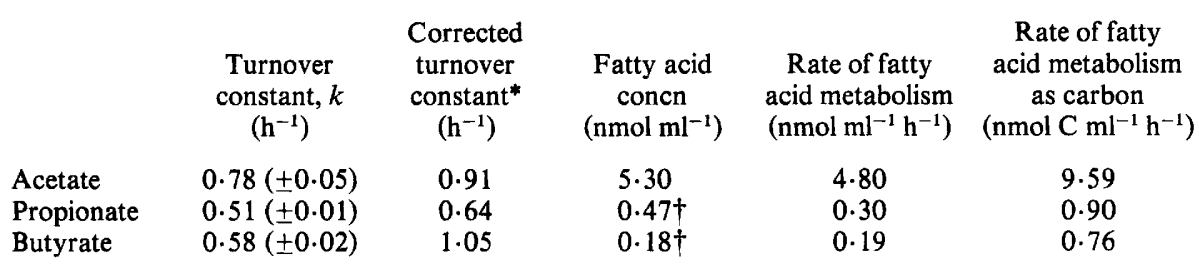

* $k$ corrected to 'zero injected volume' of radiotracer.

$\dagger$ Corrected for low extraction because of strong adsorption (see Discussion).

Correlation coefficients $(r)$ for turnover constant $(k)$ : for acetate, 0.98 ; for propionate, 0.94 ; for butyrate, 0.99 . 


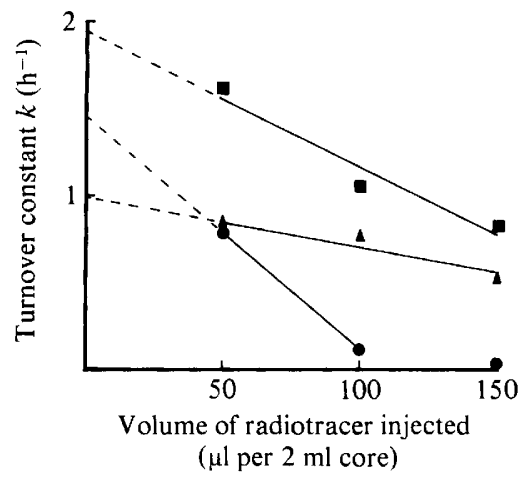

Fig. 3. Effect on the turnover constant $(k)$ of changing the injected amount of radiotracer solution: $\left[\mathrm{U}-{ }^{14} \mathrm{C}\right]$ acetate $(\Delta) ;\left[2-{ }^{14} \mathrm{C}\right]$ propionate $(\square) ;\left[1-{ }^{14} \mathrm{C}\right.$ lbutyrate $(\mathbf{O})$.

Table 2. Turnover of acetate and rates of acetate metabolism in intact sediment cores from three depths in a saltmarsh pan at $6.5^{\circ} \mathrm{C}$

$\begin{array}{cccc}\begin{array}{c}\text { Depth } \\ (\mathrm{cm})\end{array} & \begin{array}{c}\text { Corrected } \\ \text { turnover } \\ \text { constant } \\ \left(\mathrm{h}^{-1}\right)\end{array} & \begin{array}{c}\text { Acetate } \\ \text { concn } \\ \left(\mathrm{nmol} \mathrm{ml}^{-1}\right)\end{array} & \begin{array}{c}\text { Rate of acetate } \\ \text { metabolism } \\ \left(\mathrm{nmol} \mathrm{ml}^{-1} \mathrm{~h}^{-1}\right)\end{array} \\ 0-4 & 0.48( \pm 0.05) & 16.14 & 7.75 \\ 5-9 & 0.207( \pm 0.02) & 11.55 & 2.39 \\ 18-22 & 0 & 8.23 & 0\end{array}$

* $k$ corrected to 'zero injected volume' of radiotracer.

Correlation coefficients $(r)$ for turnover constant $(k)$ : $0-4 \mathrm{~cm}, 0 \cdot 98 ; 5-9 \mathrm{~cm}, 0 \cdot 97 ; 18-22 \mathrm{~cm}, 0 \cdot 26$.

available. The maximum volume injected $(150 \mu \mathrm{l})$ represented only about a $9 \%$ dilution of the sediment pore water, and the $50 \mu \mathrm{l}$ routinely injected was less than $3 \%$. It is unlikely, therefore, that the observed effect was due to dilution, but rather was a concentration effect as the injected radiotracers increased the available pool size of each fatty acid. Thus, our technique is not a true tracer technique as the injected radiolabelled substrate did influence the measured turnover. The observed effect was greatest with butyrate which generally had the lowest pool size, and least with acetate which had the greatest pool size. However, it was possible, on the basis of Fig. 3, to correct the measured turnover constants for the effect of the added radiotracer. Both acetate and propionate showed an approximately linear relationship between $k$ and the injected volume of radiotracer. By extrapolating the graph for each acid back to the vertical axis it was possible to deduce the theoretical value of $k$ when no radiotracer was injected (at 'zero injected volume' of radiotracer). Routinely, $50 \mu \mathrm{l}$ of radiotracer was injected and, from Fig. 3, the relationships between the value of $k$ measured with $50 \mu \mathrm{l}$ radiotracer and that at 'zero injected volume' could be deduced. These factors were 1.16 for acetate, and 1.25 for propionate. The values of $k$ measured with $50 \mu$ of injected radiotracer were therefore corrected by these factors to compensate for the effect of the added volume of radiotracer upon the turnover constants.

With butyrate there was little turnover when $150 \mu$ of radiotracer was injected and the line drawn between the $50 \mu \mathrm{l}$ and $100 \mu \mathrm{l}$ values was extrapolated back to deduce the correction factor (1.81). A minimum value (1.45) would be obtained by extrapolating back the line drawn between the $50 \mu \mathrm{l}$ and $150 \mu \mathrm{l}$ points. Thus the probable limits for the correction factor for butyrate are 1.45 to 1.81 , and the greater estimate was used to avoid any underestimate of the importance of butyrate in carbon flow. Again, the turnover constants for butyrate were corrected, using this factor. 
Acetate turnover and acetate concentration both decreased with increasing depth (Table 2). At $18-22 \mathrm{~cm}$ no acetate turnover could be detected.

The final slurry experiments showed that propionate and butyrate were actively metabolized in the absence of molybdate $\left[k\right.$ for propionate $=0.32( \pm 0.07) \mathrm{h}^{-1} ; k$ for butyrate $=0.37( \pm 0.05) \mathrm{h}^{-1}$, but the presence of $20 \mathrm{mM}$-molybdate totally inhibited turnover of both of these fatty acids $\left[k=0 \mathrm{~h}^{-1}\right.$ for both propionate and butyrate].

\section{DIS CUSSION}

The semilogarithmic plots of residual radioactivity in the injected fatty acid pools revealed biphasic removal of propionate and butyrate from the extractable pools of each fatty acid (Fig. 1). In contrast, acetate showed a single rate of decrease. Sediment cores that had been autoclaved (Fig. 2) still showed the initial removal of radioactivity from ${ }^{14} \mathrm{C}$-labelled propionate and butyrate but no further removal occurred after this. This observation strongly suggested that the initial decrease was at least partly the result of exchange of the injected ${ }^{14} \mathrm{C}$-labelled fatty acid between the extractable fatty acid pool and a tightly bound pool of fatty acid which was not recoverable with our extraction method. The binding sites for such adsorbed fatty acids are probably to be found on the surfaces of the sediment particles. As our extraction method involved acidification of the whole sediment before the aqueous phase was removed and extracted with ether, it is possible that the concentrations measured included not only the dissolved fatty acid pool but also any weakly bound fatty acids which were desorbed by acidification. Acetate did not apparently adsorb strongly during the period of the experiment as there was no evidence of removal by exchange with a tightly bound pool. In contrast, Ansbaek \& Blackburn (1980) suggested that 3\% of injected radiolabelled acetate adsorbed strongly to sediment from Limfjord, Denmark.

Clearly, the comparison of autoclaved and unautoclaved sediment samples (Fig. 2) showed that biological removal of acetate occurred; while in the cases of propionate and butyrate the second, slower, rate of removal was also due to biological activity. Comparison of the calculated turnover constants for propionate and butyrate in the initial and secondary (biological) stages of removal suggested that exchange accounted for $63 \%$ of the initial rate of removal of labelled propionate, and $78 \%$ of the initial rate of removal of labelled butyrate. Christensen \& Blackburn (1980) have similarly presented evidence of non-biological removal of $\left[{ }^{14} \mathrm{C}\right]$ alanine by adsorption in saltmarsh sediment which had been biologically inactivated by incubation at $-3{ }^{\circ} \mathrm{C}$.

It is not known whether each of the fatty acid pools within the sediment (that is, dissolved, weakly adsorbed, strongly adsorbed) is equally available for microbiological utilization. Clearly, if the tightly bound pools of propionate and butyrate were still available for metabolism their total available pool sizes will have been underestimated as the extracted fatty acids did not include the tightly bound pools. However, it is possible to use the data from the autoclaved sediment cores to estimate the magnitude of the exchange between extractable and tightly bound pools as this process was complete after $20 \mathrm{~min}$, and biological removal did not occur. These data (Fig. 2) showed that $22 \%$ of the propionate and $14 \%$ of the butyrate were removed from the extractable pool of each fatty acid by exchange with a tightly bound pool. The fatty acid concentrations in Table 1 have therefore been corrected to compensate for this underestimation.

The investigation of the effect of the injected volume of radiotracer solution upon $k$ showed that the calculated value of $k$ decreased with increasing volumes of radiotracer (Fig. 3). Similar observations have been reported for both $\left[{ }^{14} \mathrm{C}\right.$ lacetate (Ansbaek \& Blackburn, 1980) and $\left[{ }^{14} \mathrm{C}\right]$ alanine (Christensen \& Blackburn, 1980) in marine sediments. The latter authors attributed this to the amount of injected tracer exceeding the existing capacity of the sedimentary bacteria to increase their metabolic rate in response to the increased pool size, with $k$ consequently diminishing. Such an explanation requires that a factor other than fatty 
acid concentration, perhaps bacterial numbers, limits the rate of fatty acid metabolism. In our study this explanation seems feasible as the proportionate effect of increased amounts of injected tracer was least with acetate, which had the greatest pool size, and greatest with butyrate, which generally had the smallest pool size. However, by extrapolating the graphs shown in Fig. 3 to 'zero injected volume' it was possible to correct such errors.

The concentration of acetate within the surface sediment was much greater than that of either propionate or butyrate, and the rate of turnover of acetate was also the greatest (Table 1). If the differing molar carbon content of each acid was taken into account, the rates of carbon flow through acetate, propionate and butyrate were in the proportion of $12 \cdot 6: 1 \cdot 2: 1 \cdot 0$. This emphasizes the importance of acetate as a major terminal product of organic carbon metabolism from a variety of precursors. These precursors may include polysaccharides, aromatic polymers such as lignins, proteins and amino acids, and also long-chain fatty acids. However, if it is assumed that all of the propionate and butyrate was metabolized to acetate, the calculated rates of turnover show that at most only $6.0 \%$ of the acetate can have been derived from propionate, and $7.9 \%$ from butyrate. That is, the majority of the acetate came from precursors other than propionate or butyrate. Further work is required to identify the other major sources of acetate.

Although carbon flow through acetate was rapid in the surface layer of sediment, this decreased markedly with increased depth (Table 2). Acetate turnover was undetectable at $18-22 \mathrm{~cm}$, and at $5-9 \mathrm{~cm}$ was only $31 \%$ of the rate in the $0-4 \mathrm{~cm}$ layer. Sulphate-reducing bacteria are the major acetate-utilizers in the Colne Point saltmarsh sediment (Banat et al., 1981), and it has also been demonstrated (Nedwell \& Abram, 1978) that sulphate reduction rates diminish by two orders of magnitude between the surface layer and $20 \mathrm{~cm}$ depth. Our data provide further circumstantial evidence of the link between acetate oxidation and sulphate reduction. Other measurements of microbial activity have also shown extremely low rates below the surface $0-5 \mathrm{~cm}$ layer (Abd. Aziz \& Nedwell, 1979).

Sørensen et al. (1981) have attributed propionate and butyrate turnover in sediment from a coastal lagoon to the activity of sulphate-reducing bacteria. Our data also show that propionate and butyrate turnover was inhibited by $20 \mathrm{~mm}$-molybdate, indicating the presence of propionate- and butyrate-metabolizing sulphate-reducers with the metabolic capabilities of those described by Laanbroek \& Pfennig (1981) and Widdel (1980). Moreover, the total inhibition of propionate and butyrate turnover by molybdate strongly suggests that sulphate-reducing bacteria are the sole major group responsible for such turnover.

We would like to thank the Essex Naturalists' Trust for permission to work on their Colne Point Nature Reserve. This work was supported by a grant (GR3/3945) to D. B. N. from the Natural Environment Research Council, U.K.

\section{REFERENCES}

ABD. AzIz, S. A. \& Nedwell, D. B. (1979). Microbial nitrogen transformations in the salt marsh environment. In Ecological Processes in Coastal Environments, pp. 385-398. Edited by R. L. Jefferies \& A. J. Davy. Oxford: Blackwell Scientific Publications.

Ansbaek, J. \& BlackBurN, T. H. (1980). A method for the analysis of acetate turnover in a coastal marine sediment. Microbial Ecology 5, 253-264.

Banat, I. M., Lindström, E. B., Nedwell, D. B. \& BALBA, M. T. (1981). Evidence for the coexistence of two distinct functional groups of sulfate-reducing bacteria in saltmarsh sediment. Applied and Environmental Microbiology 42, 985-992.

BRYANT, M. P. (1977). Microbiology of the rumen. In Duke's Physiology of Domestic Animals, pp. 287-
304. Edited by M. J. Swain. Ithaca, N.Y.: Cornell University Press.

Christensen, D. \& Blackburn, T. H. (1980), Turnover of tracer $\left({ }^{14} \mathrm{C},{ }^{3} \mathrm{H}\right.$ labelled) alanine in inshore marine sediments. Marine Biology 58, 97-103.

Hobson, P. N., Bousfield, S. \& Summers, R. (1974). Anaerobic digestion of organic matter. Critical Reviews in Environmental Control 4, 131-191.

LaAnbroek, J. H. \& Pfennig, N. (1981). Oxidation of short-chain fatty acids by sulfate-reducing bacteria in freshwater and marine sediments. Archives of Microbiology 128, 330-335.

Miller, D., Brown, C. M., Pearson, T. H. \& STANLEY, S. O. (1979). Some biologically impor- 
tant low molecular weight organic acids in the sediments of Loch Eil. Marine Biology 50, 375-383.

NedWell, D. B. \& ABraM, J. W. (1978). Bacterial sulfate reduction in relation to sulfur geochemistry in two contrasting areas of saltmarsh sediment. Estuarine and Coastal Marine Science 6, 341-351.

Oremland, R. W. \& TAYlor, B. F. (1978). Sulphate reduction and methanogenesis in marine sediments. Geochimica et cosmochimica acta 42, 209-214.

PECK, H. D. (1959). The ATP dependent reduction of sulfate with hydrogen in extracts of Desulfovibrio desulfuricans. Proceedings of the National Academy of Sciences of the United States of America 45, 701-708.
Sørensen, J., Christensen, D. \& Jørgensen, B. B. (1981). Volatile fatty acids and hydrogen as substrates for sulfate-reducing bacteria in anaerobic marine sediment. Applied and Environmental Microbiology 42, 5-11.

WIDDEL, F. (1980). Anaerober Abbau von Fettsauren und Benzoesaure durch neu isolierte Arten sulfatreduzierender Bakterien. Doctoral dissertation, University of Gottingen, F.R.G.

Wolfe, R. S. \& Higgins, I. J. (1979). Microbial biochemistry of methane-a study in contrasts. In Microbial Biochemistry, International Review of Biochemistry, vol. 21, pp. 268-300. Edited by J. R. Quayle. Baltimore: University Park Press. 